\title{
Major breakthroughs in hand surgery
}

\author{
SP Chow
}

From 10th Congress of the Asia-Pacific Federation of Societies of Surgery fo the Hand and the 6th Congress of Asia-Pacific Federation of Societies of Hand Therapists

Kuala Lumpur, Malaysia. 2-4 October 2014

During my 40 years of involvement with hand surgery, I have witnessed the following major breakthroughs:

- Tendon surgery and tendon program

- Development of artificial finger joints

- Microsurgery

- Various fixation systems for fractures

- Wrist arthroscopy

Certain breakthroughs are appearing in the horizon:

- 3-D printing

- Tissue engineering

- Genetic engineering

- Intra-uterine surgery

At organizational level, the following are also important:

- Team approach for rehabilitation

- IFSSH, APFSSH, national societies

However, all these technical and scientific advances should be guided by future breakthroughs in the arts and humanities of medicine - the love and care for our patients. 